\title{
HIV/AIDS awareness and attitude among factory workers in Shiraz, Iran
}

\author{
Behzad Dehghani ${ }^{1}$, Zeinab Shahsavani², Abbas Dehghani ${ }^{1, *}$ \\ 'Department of Bacteriology and Virology, School of Medicine, Shiraz University of Medical Sciences, Shiraz, Iran \\ 2Student Research Committee, School of Nutrition and Food Sciences, Shiraz University of Medical Sciences, Shiraz, Iran
}

\begin{abstract}
HIV has been introduced as a causative agent for AIDS which is still considered as a major health problem for the country and a burden on the health care system. Raising awareness and knowledge plays a critical role in controlling HIV infection in all social groups. Therefore, this study aimed to investigate the awareness and attitudes of factory workers regarding HIV/AIDS infection in Shiraz, Iran. This cross-sectional study was conducted on 92 factory workers in Shiraz, selected via the random sampling technique. A standard researchermade questionnaire was used to collect data. Around $84 \%$ of participants were male and $65.2 \%$ had 30 years of age or more. The majority of responders considered shared syringe as the main transmission route in Iran. The awareness level of the general aspects of HIV infections and possible transmission modes were high. A large proportion of responders believed that patients should be supported by the governments and that they have the right to lead a normal life, meanwhile they were scared for their children having an infected classmate. It can be concluded that the public programs to increase awareness had a positive effect on factory workers' knowledge. However, some misconceptions toward HIV patients were identified that need to be corrected. In addition, further studies should be conducted in other cities to reach an accurate estimate of HIV/AIDS awareness among factory workers as a big part of our society.
\end{abstract}

Key words: HIV, AIDS, Awareness, Factory workers, Iran

\section{Introduction}

Acquired immune deficiency syndrome (AIDS) has started to spread since 1970 s rapidly and became a mysterious pandemic in the 1980 ; it was revealed that human immunodeficiency virus (HIV) caused AIDS. Since then, it has emerged as the most difficult challenge to public health $[1,2]$.

The most recent WHO report estimated people living with HIV at the end of 2019 around 38 million [3]. Although the four main HIV transmission routs includes unprotected sexual intercourse, contaminated blood transfusion, breast milk, transmission from an infected mother to her baby at birth, this report introduced sexual intercourse as the main transmission route especially among the age group 15-49 years [3, 4].

While in most regions of the world a decline of the epidemic has been reported, in the Middle East and North Africa regions a growing epidemic among key populations has been indicated recently [4]. Based on the recent reports from Iran, it was estimated that 59,000 [5] individuals are living with the HIV and based on previous studies, sexual intercourse, needle sharing, and mother to child transmission have been reported as the main routes of AIDS transmission [6].

\footnotetext{
* Corresponding author:

Abbas Dehghani, MSc

Department of Bacteriology and Virology, School of Medicine,

Shiraz University of Medical Sciences, Shiraz, Iran

Tel/Fax: +98 7132304356

Email: abbasdeh@mail.ir

https://orcid.org/oooo-0002-2386-7454
}

Received: April, 08, 2021

Accepted: May, 07, 2021

Prevention of HIV infections was suggested as the most cost-effective measure to control this disease which needs to raise awareness in all social groups of a country [7], and risky practices and insufficient knowledge are major burdens in preventing the spread of HIV. During the last decades, several public programs were conducted to increase HIV/ADIS awareness in Iran and several studies tried to assess knowledgeand attitude toward this disease in different parts of the society. A large proportion of studies have focused on some specific groups including students [8, 9], medical staff [10, 11], and hairdressers [12, 13], and it seemed factory workers who consist a large part of our society were ignored. With this background in mind, the aim of this study was to evaluate the knowledge and attitudes toward HIV infection and assess the effect of public programs among factory workers in Shiraz, South Iran.

\section{Materials and Methods}

\subsection{Study area}

In this cross-sectional study, 92 workers enrolled who were randomly selected from different firms in Shiraz, South Iran, during 2017-2018. A standardized questionnaire previously designed by our research group was used including a series of questions about HIV infection, different transmission routes, and treatment.

Different inclusion criteria were considered including, 1) Iranian nationality, 2) being Muslim, 3) working in a firm in Shiraz, and 4) HIV-negative status. In addition, participants with relatives suffering from HIV/AIDS were excluded. To assess the reliability of the questionnaire, it was administered to 15 participants two times with a retest interval of a week, which showed moderate-to-high reproducibility.

\subsection{Measurements}

Data were collected through a standardized questionnaire containing 26 questions. The questionnaire was considered to be flexible to responders and they were able to answer any question even though they were not informed in this regard.

\subsection{Statistical analysis}

In the present study, the sample size was calculated using Cochran's formula, and the estimated power was around 0.8 , which was acceptable. To evaluate the construct and concurrent reliabilities the Cronbach's Alpha coefficient was used. Besides, the Pearson's product-moment correlation was employed to analyze the confirmatory and explanatory factors. All data were coded using Microsoft Excel (Microsoft, Mountain View, CA), and data analysis was performed using the SPSS, version 22 (IBM Corp., Somers, NY). Chi-square test and cross tabulation were used to compare groups and a p-value of $<0.05$ was considered statistically significant.

\section{Results}

In all 92 workers enrolled, of which $83.7 \%$ were male, the majority of participants were more than 30 years old (65.2\%), the education level of the majority of them was high school diploma (42.4\%) and the majority of participants had diploma (42.4\%).

Our results showed that the majority of the workers (96.1\%) involved in the study had heard about HIV/AIDS. Table 1 also shows the results of the participants' knowledge and reveals that generally their awareness about HIV and AIDS was satisfied and the mean of correct answers for questions was $80.6 \%$. Around $96 \%$ believed that AIDS is a serious disease and adherence to moral principles can prevent the spread of AIDS.

Out of 89 participants who answered the question about the major HIV transmission route in Iran, $73.9 \%$ selected shared syringes used by addicted people. Besides, $16.3 \%$ and $6.5 \%$ of them believed sex and blood transfusion are the other transmission routes of AIDS in Iran, respectively.

The results of awareness about HIV transmission methods showed $95.7 \%$ of participants believed that contaminated dental and surgical instruments as well as sexual intercourse (marriage) could transmit this virus. Furthermore, the percentage of responders believed that donated organs (blood or tissue) and mother to baby through womb can spread HIV were $94.6 \%$ and $92.4 \%$, respectively. Moreover, more than half of responders (52.2\%) believed that HIV can be transmitted via breastfeeding.

A large percentage of the responders did not consider sharing the items or places belong to AIDS/HIV patients including the swimming pool or bathrooms with the AIDS patients (73.9\%), HIV patients' personal items (55.4\%) (i.e., clothes, comb, towel, etc.), their tear (excreta) (70.7\%), touching the AIDS patients (88\%), using the items and food of 
AIDS patients (69.6\%), as the HIV transmission routes. It was noticeable that $85 \%$ feared using the AIDS patient's razor (shaver).

Table 2 shows the workers' attitude toward HIV infected patients. Comparison study based on sex, age, and education level revealed that in all cases there was no significant difference among participants groups.

\section{Discussion}

Compared to two previous studies conducted by this research group in Shiraz which studied awareness among high school students [9] and college students [14]; it can be concluded factory workers and high school student share the same idea and, in both groups, more than $50 \%$ believe that HIV infections is

Table 1. The responders' knowledge on HIV/AIDS

\begin{tabular}{lcc}
\hline General knowledge & $\begin{array}{c}\text { Correct answer } \\
(\mathbf{\%})\end{array}$ & $\begin{array}{c}\text { Dose not know } \\
(\mathbf{\%})\end{array}$ \\
\hline Is AIDS caused by a virus? & 84.8 & 13 \\
\hline Is AIDS a contagious disease? & 94.6 & 5.4 \\
\hline Is AIDS a hereditary disease? & 81.5 & 0 \\
\hline Is AIDS a curable disease? & 87 & 1.1 \\
\hline Is AIDS mostly observed in developing or underdeveloped countries? & 20.7 & 2.2 \\
\hline Is AIDS a serious disease or as simple as catching a cold? & 95.7 & 0 \\
\hline Does a person infected with HIV have a less resistant body against other diseases? & 92.4 & 0 \\
\hline Is there any vaccine against HIV infection? & 83.7 & 1.1 \\
\hline Can Patient have Negative diagnosis results? & 53.3 & 1.1 \\
\hline Does a person transmit the HIV virus without showing the AIDS symptoms? & 80.4 & 1.1 \\
\hline Will morality prevent the spread of AIDS? & 95.7 & 0 \\
\hline Can controlling the blood of donators be effective to prevent the spread of HIV? & 90.2 & 0 \\
\hline Can the sterilization of dental instruments by dentists prevent AIDS infection? & 95.7 & 0 \\
\hline Will early diagnosis of HIV virus in people help the prevention of AIDS infection? & 76.1 & 2.2 \\
\hline Which part of body is affected by HIV virus? & 83.7 & 5.4 \\
\hline Which method is used to detect HIV virus in blood? & 75.5 & 1.1 \\
\hline
\end{tabular}

Table 2. The responders' attitudes towards HIV/AIDS patients

\begin{tabular}{|c|c|c|c|c|c|c|}
\hline General attitudes & $\begin{array}{c}\text { Totally } \\
\text { agree } \\
(\%)\end{array}$ & $\begin{array}{c}\text { Agree } \\
(\%)\end{array}$ & $\begin{array}{c}\text { No } \\
\text { comment } \\
(\%)\end{array}$ & $\begin{array}{l}\text { Disagree } \\
(\%)\end{array}$ & $\begin{array}{l}\text { Completely } \\
\text { disagree } \\
(\%)\end{array}$ & $\begin{array}{c}\text { Dose not } \\
\text { answer } \\
(\%)\end{array}$ \\
\hline $\begin{array}{l}\text { Students infected with HIV virus should be } \\
\text { educated in a separate school }\end{array}$ & 39.1 & 17.4 & 12 & 16.3 & 15.2 & 0 \\
\hline $\begin{array}{l}\text { If our children have a HIV infected classmate, } \\
\text { we should change the school of our children }\end{array}$ & 38.0 & 17.4 & 13.0 & 20.7 & 10.9 & 0 \\
\hline HIV infected patients should be supported & 70.7 & 28.3 & 1.1 & 0 & 0 & 0 \\
\hline $\begin{array}{l}\text { HIV infected patients must benefit from social } \\
\text { rights such as studying, working, ... }\end{array}$ & 63.0 & 30.4 & 3.3 & 1.1 & 2.2 & 0 \\
\hline $\begin{array}{l}\text { We must allow the AIDS patient to use public } \\
\text { bathrooms or swimming pools. }\end{array}$ & 30.4 & 28.3 & 18.5 & 8.7 & 14.1 & 0 \\
\hline $\begin{array}{l}\text { One of the main reasons of AIDS infection is } \\
\text { disobeying religious and moral principles }\end{array}$ & 46.7 & 39.1 & 8.7 & 5.4 & 0 & 0 \\
\hline $\begin{array}{l}\text { People should be aware of AIDS disease since } \\
\text { it's a health and public issue }\end{array}$ & 83.7 & 14.1 & 2.2 & 0 & 0 & 0 \\
\hline
\end{tabular}


mainly found in developing and underdeveloped countries. Although, in contrary, around $70 \%$ of college students disagreed with this idea.

Interestingly in all three reports, responders considered the shared syringe among addicted people as the major transmission route in Iran, along with, in second and third ranks, sex and blood transfusion were placed.

Knowledge about transmission methods in three studies showed similarity in some cases including contaminated medical instruments, sexual intercourse, donated organs (or blood), and mother to baby through the womb which were appropriately high in all studies.

While, in extremely rare cases, HIV can be transmitted by sharing razors, using the AIDS patient's razor was considered by $74.2 \%$ of college students, $76 \%$ high school students, and $85 \%$ factory workers as a mode of transmission.

It is established that breastfeeding substantially increases the risk of HIV-1 transmission from mother to child [15], the awareness about this route amongst high school students was $62 \%$ which was higher than factory workers (52.2\%) and significantly higher than college students (42.7\%).

Comparison results of three studies in misconceptions about modes of transmission showed high school students had the highest rates of misconceptions. Using HIV patients' personal items showed varied results, while only $18.2 \%$ of college students feared of using shared personal items, this subject was significantly high among factory workers (44.6\%) and high school students (67\%). Additionally, sharing the swimming pool or bathrooms was considered by $15 \%$ of college students, $32 \%$ of high school students, and $\mathbf{2 6 . 1 \%}$ of factory workers as a route of transmission. Besides, $8 \%$ of college students, $18 \%$ of high school students, and $12 \%$ of workers considered touching as a route. Also urine, tears, and saliva was recognized as a spread way by $25.2 \%, 24 \%$, and $29.3 \%$ of college students, high school students, and factory workers, receptively.

College students showed the best attitude toward HIV patients in comparison with high school students and factory workers. While a majority of college students disagreed with using separate schools for HIV infected students and changing the school if there is an HIV positive classmate; the majority of high school students and workers agreed with these subjects. Furthermore, contrary to the majority of high school students who believed that public bathrooms or swimming pools are not supposed to be available for AIDS patients, the majority of college students, and workers thought they must be allowed to use these facilities.

To the best of our knowledge, there was no published study on HIV awareness in factory workers in Iran as well as limited studies were done in other countries. Mullany et al., 2003 researched to assess HIV awareness among 725 Burmese migrant factory workers in Tak Province, Thailand [16]. The average percentage of questions answered correctly about HIV transmission was $41.3 \%$ which was lower than our results which were around $77 \%$. Besides, only $12 \%$ of Burmese workers believed that HIV was not transmitted through casual contact (kissing, coughing, sharing a toilet, etc.) which was significantly higher in the present study (88\%). In general, it can be concluded that the level of awareness in the present study was significantly higher than in Mullany's study. In another study, Abera et al., 2003 conducted a crosssectional study to investigated HIV/AIDS awareness among Workers in the informal sector in Ethiopia [17]. While, in the present study we could not define any different between male and female responders, in Abera's study females were less aware than males. Furthermore, 88\% Ethiopian workers considered sex as a rout of transmission which was lower than our results (95.7\%). Only $13.9 \%$ of Ethiopian workers found HIV patients' personal items as the HIV transmission routes [17]; however, this was around 45\% among Iranian workers which showed a big misunderstanding about HIV transmission route. In addition, Islam et al., 2010 collected data using a questionnaire from 123 participants (female migrant workers) who were ready to fly from Bangladesh to other countries to take up an overseas job. Similar to our result the majority of Bangalees workers were familiar with potential modes of acquiring HIV infection. Contrary to our study, only $46.3 \%$ of Bengalese workers found unprotected sex as a potential mode of HIV infection, while it was $95.7 \%$ among Iranian workers [18].

Hasan et al., 2013 [19] investigated the level of awareness on HIV/AIDS amongst the garment workers in Bangladesh. In this study, 303 workers in three selected garment factories in Dhaka city were enrolled. Similar to our study the vast majority of 
workers knew AIDS as a transmissible and preventable disease. Contrary to our results, Bangalees workers believed that sexual intercourse is the main route of HIV transmission; however, Iranian workers considered shared syringe as the major route which may be related to different social disorders in Iran and Bangladesh. Additionally, while, Hasan et al., showed the level of awareness increased significantly with age; in the present study, we did not find any relationship.

The main limitation of the present study was the inclusion of 92 factory workers, which was due to the short duration of the study. Hence, the sample size was too small to find a comprehensive perspective on the level of awareness among workers. However, our results could show the level of knowledge about the transmission and treatment of HIV/AIDS which can be practical for further studies.

In general, the HIV/AIDS awareness of factory workers was satisfactory and in many cases, the prevalence of correct answers was higher than 90\%. It seems there is no need to raise awareness about general aspects of HIV/AIDS and their transmission routes. However, there are some misconceptions and misunderstandings toward HIV-positive patients, especially regarding infected students which showed the immediate need of raising awareness.

\section{Acknowledgments}

The authors would like to acknowledge all the study participants and Ali Dehghani and Yalda Dehghani for their invaluable assistance in editing this manuscript.

\section{Author contributions}

Conception or design of the work: BD and ZS; Data collection: ZS, AD; Data analysis and interpretation: $\mathrm{BD}$, $\mathrm{ZS}$; Drafting the article: $\mathrm{BD}, \mathrm{AD}$; Critical revision of the article: BD, AD. All authors read and approved the final version of manuscript.

\section{Conflict of Interests}

The author(s) declared no potential conflicts of interest with respect to the research, authorship, and/or publication of this article.

\section{Ethical declarations}

The researchers obtained the approval of the Human Research Ethics Committee of the University. In addition, prior to the study, the written informed consent forms were read and signed by each participant in the study.

\section{Financial support \\ Self-funded study.}

\section{References}

1. UNAIDS. Report on the global HIV/AIDS epidemic July 2002. Available from: http://data.unaids.org/pub/report/2002/brglobal_aids_report_ en_pdf_red_en.pdf

2. Jaiswal S, Magar BS, Thakali K, Pradhan A, Gurubacharya DL. HIV/AIDS and STI related knowledge, attitude and practice among high school students in Kathmandu valley. Kathmandu Univ Med J (KUMJ). 2005; 3(1):69-75.

3. UNAIDS. Global HIV \& AIDS statistics - Fact sheet. Available from: https://www.unaids.org/en/resources/fact-sheet

4. Mumtaz GR, Riedner G, Abu-Raddad LJ. The emerging face of the HIV epidemic in the Middle East and North Africa. Curr Opin HIV AIDS. 2014; 9(2):183-91.

5. UNAIDS. Epidemic transition metrics. People living with HIV. Islamic Republic of Iran. Available from: https://www.unaids.org/en/regionscountries/countries/islamicr epublicofiran

6. WHO, UNODC, UNAIDS. Technical Guide for countries to set targets for universal access to HIV prevention, treatment and care for injecting drug users. Available from: https://www.unaids.org/sites/default/files/sub_landing/idu_tar get_setting_guide_en.pdf

7. Bertozzi S, Padian NS, Wegbreit J, et al. HIV/AIDS Prevention and Treatment. In: Jamison DT, Breman JG, Measham AR, et al., editors. Disease Control Priorities in Developing Countries. 2nd edition. Washington (DC): The International Bank for Reconstruction and Development / The World Bank; 2006. Chapter 18.1 Available from: https://www.ncbi.nlm.nih.gov/books/NBK11782/ Co-published by Oxford University Press, New York.

8. Dadipoor S, Shahsavari S, Ghaffari M, Rakhshanderou S, SafariMoradabadi A. Iranian school students' awareness of and attitude towards HIV/AIDS: a systematic review. Int J Adolesc Youth. 2020; 25(1):240-50.

9. Dehghani A, Dehghani P, Dehghani B. HIV/AIDS Knowledge and Attitude among High School Students in Shiraz, Iran in 2015. J of Midwifery Reprod Health. 2017; 5(2):897-903.

10. Askarian M, Hashemi Z, Jaafari P, Assadian O. Knowledge about HIV infection and attitude of nursing staff toward patients with AIDS in Iran. Infect Control Hosp Epidemiol. 2006; 27(1):4853 .

11. Rostamzadeh M, Afkhamzadeh A, Afrooz S, Mohamadi K, Rasouli MA. Dentists' knowledge, attitudes and practices regarding Hepatitis B and C and HIV/AIDS in Sanandaj, Iran. BMC Oral Health. 2018; 18(1):220.

12. Ataei B, Shirani K, Alavian SM, Ataie M. Evaluation of Knowledge and Practice of Hairdressers in Women's Beauty Salons in Isfahan About Hepatitis B, Hepatitis C, and AIDS in 2010 and 2011. Hepat Mon. 2013; 13(3):e6215.

13. Gholamrezaee Sarvelat Z, Sharifirad G, Zamanian H, Mohebi S. Effect of Educational Intervention Based on the Health Belief 


\section{Dehghani et al.}

Model on the Improvement of the Health Performance of Female Hairdressers in Qom, Iran. Arch Hyg Sci. 2020; 9(2):109-20.

14. Dehghani B, Dehghani A, Sarvari J. Knowledge and Awareness Regarding Hepatitis B, Hepatitis C, and Human Immunodeficiency Viruses Among College Students: A Report From Iran. Int Q Community Health Educ. 2020; 41(1):15-23. 15. John-Stewart G, Mbori-Ngacha D, Ekpini R, Janoff EN, Nkengasong J, Read JS, et al. Breast-feeding and Transmission of HIV-1. J Acquir Immune Defic Syndr. 2004; 35(2):196-202. 16. Mullany LC, Maung C, Beyrer C. HIV/AIDS knowledge, attitudes, and practices among Burmese migrant factory workers in Tak Province, Thailand. AIDS Care. 2003; 15(1):63-70.
17. Abera Z. Knowledge, attitude and behavior (KAB) on HIV/AIDS/STDs among workers in the informal sector in Addis Ababa. Ethiop J Health Dev. 2003; 17(1):53-61.

18. Islam MM, Conigrave KM, Miah MS, Kalam KA. HIV awareness of outgoing female migrant workers of Bangladesh: a pilot study. J Immigr Minor Health. 2010; 12(6):940-6.

19. Hasan AH, Hassan R, Khan ZR, Nuzhat E, Arefin U. Influence of socio-demographic factors on awareness of HIV/AIDS among Bangladeshi garment workers. Springerplus. 2013; 2(1):174. 